\title{
The effect of complementing opuntia cactaceae in normocaloric diet in patients with dyslipidemia
}

\begin{abstract}
Background/objectives: Dyslipidemia is a public health problem. The main causes of dyslipidemia are sedentary lifestyle, excessive intake of saturated fats and low intake of dietary fiber. Opuntia Cactaceae contains high levels of fiber, which is known to decrease intestinal absorption of lipids. The objective of this study is to determine the lipid-lowering effect of a normal-calorie diet supplemented with Opuntia Cactaceae in patients with dyslipidemia.
\end{abstract}

Subjects/methods: From a 160 patients with dyslipidemia group we randomly assigned two groups according to the criteria established by the World Health Organization, a control group and an experimental group. Baseline levels of cholesterol, triglycerides and fasting glucose were obtained, secondly, a Harris-Benedict normocaloric diet was calculated and anthropometric measurements were performed in both groups. The experimental group received 100g of Opuntia Cactaceae supplementation in their diet for a month.

Results: We compared cholesterol and triglycerides levels at baseline and at the end of the study on both groups. There was a statistically significant difference $(\mathrm{P}<0.001)$ of lower levels of cholesterol and triglycerides in the group receiving Opuntia Cactaceae in their diet.

Conclusion: A normo-caloric diet supplemented with Opuntia Cactaceae helps lower cholesterol levels and importantly triglyceride levels. We suggest that a normo caloric diet supplemented with Opuntia Cactaceae in patients with dyslipidemia has lipid lowering effects.

\author{
Volume 4 Issue 2 - 2017
}

\author{
Axtle Serrano Zoraida,' José Manuel \\ Lozano Sánchez,' Luis Felipe Montaño, ${ }^{2}$ \\ Ernesto Rodríguez Ayala,' Carmina Flores- \\ Domínguez' \\ 'Centro de Investigación en Ciencias de la Salud (CICSA), \\ Facultad de Ciencias de la Salud Universidad Anáhuac México \\ Norte, NA \\ ${ }^{2}$ Department of Cell Biology and Tissue Faculty of Medicine \\ México, NA
}

\begin{abstract}
Correspondence: Carmina Flores- Domínguez, Facultad de Ciencias de la Salud, Universidad Anahuac Mexico Norte, Avenida Universidad Anahuac No. 46, Col. Lomas Anahuac, North America, CP. 52783, Tel +52 5556270210 Ext. 725I, Fax +525556270210 Ext.7250, Email carmina.flores@anahuac.mx
\end{abstract}

Received: January 14, 2016 | Published: March 07, 2017

\section{Introduction}

Dyslipidemia is defined as an abnormal increase in serum lipids, however, increased serum levels of insulin concentration, transferase and ON- acetyl glucose can also be present. ${ }^{1-3}$ Dyslipidemia is considered a chronic disease and its one of the major causes of death in our country and around the world.

\section{Risk factors}

Dyslipidemia and its risk factors (obesity, physical inactivity, diabetes mellitus, hypertension, poor diet high in saturated fat and low in fiber), have been increasing their incidence on our country for several years. It is estimated that about $15 \%$ of the Mexican population carries some form of dyslipidemia. The types of dyslipidemia may be due to digestive, liver or thyroid disorders. They can also be hereditary and secondary rise to alterations in lipid metabolism by dietary modifications. There are no modifiable risk factors such as gender, age and heredity and modifiable risk factors, those that can be corrected directly as serum lipid levels, smoking, hypertension, diabetes, alcohol and diet. And indirectly correction, such as physical inactivity, obesity, stress and oral contraceptive use. According to the World Health Organization (WHO) normal serum lipid oscillate in: Triglycerides below $150 \mathrm{mg} / \mathrm{dl}$, total cholesterol below $200 \mathrm{mg} / \mathrm{dl}$ and low density lipoprotein less than $100 \mathrm{mg} / \mathrm{dl}$. Dyslipidemia can be classified according to their origin and lipid profile. Depending on their origin, may be primary, as family dyslipidemia and may be secondary due to other pathology.

\section{Epidemiology}

Obesity is a disease that has been brought back by using the ratio of waist and hip. The fat distribution along the waist is directly related to blood pressure and blood cholesterol level. Being able to identify certain prevalence of cardiovascular risk. NHANES reports of men, women and ethnic groups reflect a dyslipidemic pattern in common: an increase in the actual amount of triglycerides, increased very low density lipoproteins (VLDL, LDL), and a decrease in high density lipoprotein cholesterol. ${ }^{4}$ The Framingham study concluded statistically, that men and women with diabetes had a higher prevalence of hypertriglyceridemia and low HDL cholesterol levels.

In Mexico, there is a higher prevalence of hypercholesterolemia in the northern states of the country. The increase is directly proportional to the age. It has an overall prevalence of $23.6 \%$ as determined by genetic predisposition and environmental factors. ${ }^{2,3}$

The most frequent dyslipidemia in Mexican population, according to a study reported in 2010 in the Journal of Public Health of Mexico, is one in which the serum concentrations of HDL are below the values recommended by WHO, $<40 \mathrm{mg} / \mathrm{dl}$ for men and $<50 \mathrm{mg} / \mathrm{dl}$ for women; the second most frequent abnormality in the Mexican population was dependent LDL cholesterol, however, and in relation to the results of this study, it was observed that $31.5 \%$ of Mexicans present with hypertriglyceridemia.

\section{Hypercholesterolemia and hypertriglyceridemia}

Cholesterol is obtained from hepatic metabolism endogenously and exogenously through food. Having excessive concentrations of serum cholesterol in the blood raises the risk of developing heart disease. The high density cholesterol adheres to other molecules of cholesterol in the blood and transported to the liver to be excreted from the body. It helps the body to prevent buildup of atheroma plaques in 
the arteries. It is recommended to maintain serum levels above $60 \mathrm{mg} /$ dl optimally. ${ }^{5}$ Triglycerides are the main compound for lipid transport in the body. Adequate fat digestion is essential for the transport of triglycerides through the intestinal mucosa can be efficient, once inside the body, the TG can supply power or be stored as fatty acids. ${ }^{5}$

\section{Dietary fiber their physiological effects}

Dietary fiber is the set of non-digestible polysaccharides by digestive tract enzymes and lignin from plant tissues. ${ }^{6}$ Food with an adequate amount of fiber include: corn, vegetables and wheat bran. The fiber may be soluble or insoluble. The insoluble is composed of substances such as cellulose, hemicellulose and lignin, are able to retain water in its structural matrix forming mixtures of low viscosity, which accelerates intestinal transit. Soluble fiber, on contact with water, increases its viscosity, which is responsible for their actions on lipid, carbohydrate metabolism and partly its anticarcinogenic potential. There is soluble fiber in oats, barley, cactus, beans, vegetables and some fruits such as oranges. ${ }^{7}$

The fiber also can be classified into poorly fermentable such as cellulose, hemicellulose, lignin, resistant starch hydrolysis, cutin, suberin or highly fermentable as are the $\beta$-glucans, pectins, gums, mucilages and inulin oligosaccharides. ${ }^{8,9}$

The most important physiological effect of the fiber is the fiber fermentation in colon contents. Diet with a high fiber content require more chewing time, which slows the speed of swallowing and this implies an increaseofsaliva which will impact on improving oral hygiene. At the level of the stomach soluble fibers, due to its viscosity, slows gastric emptying and increase abdominal distension, which prolongs the feeling of satiety. ${ }^{10}$

In the small intestine, soluble fiber slows transit time. Also increases the thickness of the layer of water that nutrients must go through to reach solutes enterocyte membrane, which causes decreased absorption of glucose, lipid and amino acid. ${ }^{11}$ Also, there will be a decrease in the absorption of bile acids, as these residues and the phenolic uronic bind in the matrix of polysaccharides. This may alter the micelle formation and fat absorption. Depletion due to bile acid can lower cholesterol levels, to use it in the de novo synthesis of new bile acids. ${ }^{12}$

\section{Nutritional recommendations}

There are several recommendations in relation to the grams of fiber that an every-day diet should contain:

The World Health Organization (WHO) recommends a daily intake of 27-40grams of dietary fiber. Food and Drugs Administration (FDA) is proposing a consumption of $25 \mathrm{grams}$ of fiber per day per $2000 \mathrm{kcal} /$ day. The National Cancer Institute (NCI, USA) considers an optimal intake $20-30 \mathrm{~g} / \mathrm{day}$ for the prevention of colon cancer, suggesting not to exceed $35 \mathrm{~g} /$ day of dietary fiber. ${ }^{13}$

The American Dietetic Association (ADA) recommends consuming a diet containing 20-30g/day of dietary fiber, which must be 3-10grams of soluble fiber from various plant sources. In 2002, the National Academy of Sciences (NAS) established the new recommendations of dietary fiber for different biological groups, where dietary fiber intake of $25-38 \mathrm{~g} /$ day for men and women respectively from 4years of age. ${ }^{13-15}$

\section{Bromatological study of opuntia cactaceae}

The chemical composition of Cladode was evaluated using different methods by which it was determined the moisture, protein, fat, fiber, ash, carbohydrate, vitamin $\mathrm{C}$, sodium, potassium, iron and calcium levels contained in cladode of one month of age compared to cladode of one year of age.

\section{The results are the following}

Both cladodes have high water content, characteristic component of this plant, with percentages greater than $90 \%$ (92.57\% and $94.33 \%$ respectively). The percentage of fat was similar in both groups $(0.17 \%$ and $0.11 \%$ ). The percentage of carbohydrates, protein and vitamin $\mathrm{C}$ is higher in the cladode 1 month of age compared to the 1year old, $(5.96 \%$ vs. $2.43 \%$ percentage of carbohydrates, $37.27 \mathrm{mg} / 100 \mathrm{~g}$ vs. $23111 \mathrm{mg} / 100 \mathrm{~g}$, Vitamin C and $0.94 \% 0.48 \%$ of protein). The one year old cladode percentages of calcium, sodium, potassium, iron and fiber were higher than the ones obtained in the 1month old cladode, $(0.042 \%$ vs. $0.339 \%$ calcium, $0.0018 \%$ vs. $0.0183 \%$ sodium, $0.00098 \%$ vs. $0.145 \%$ potassium, 0.0792 vs. $0.322 \%$ iron, and finally $0.30 \%$ vs. $1.06 \%$ fiber).

\section{Materials/Subjects and methods}

A randomized controlled clinical trial was conducted. We randomly assigned two groups, a control group and an experimental group. Patients who came to the Health Center of Santa Cruz Ayotuxco, of both genders, aged 20-60, a BMI between 18.5 to 24.9, which had total cholesterol levels greater than $200 \mathrm{mg} / \mathrm{dl}$ and triglycerides levels greater than $150 \mathrm{mg} / \mathrm{dl}$ were selected. Patients who were receiving pharmacological treatment for dyslipidemia, enterohepatic comorbidities, active or passive smoking, blood pressure values above $130 / 90 \mathrm{mmHg}$ and glucose greater than or equal to $126 \mathrm{mg} / \mathrm{dl}$ fasting were excluded. In selected patients, were taken measurements of weight, height, BMI and blood pressure. Serum cholesterol and triglycerides were measured by taking a sample of capillary blood, which was processed by a device for quantitative measurement of total cholesterol and triglycerides "Accutrend Plus", ${ }^{14}$ thus obtaining baseline reference values for the control group and the experimental group. One normocaloric diet was calculated for each of the participants in both groups, based on their baseline requirements through the Harris Benedict equation.

In the experimental group, 100gr chopped Cactaceae Opuntia diaries, which was to be eaten before the meal. This diet was consumed for a month, the intake was monitored individually. A month later, capillary blood samples were performed in both groups, along with new anthropometric measurements.

\section{Results and discussion}

Over $50 \%$ of the patients included in this study were women (Table 1). There were two peaks of age, the first at age 30 and the second at age 55 (Graph 1). Dyslipidemia incidence at both ends of Graph1 was significantly lower than in the other groups. The intake of Opuntia Cactaceae had no effect on body weight in both groups; they remained constant throughout the study.

Table I Gender Distribution

\begin{tabular}{llllll} 
& Female & $\%$ & Male & $\%$ & Total \\
\hline Experimental Group & 43 & 53.7 & 37 & 46.3 & 80 \\
Control Group & 46 & 57.5 & 34 & 42.5 & 80 \\
Total & 89 & 55.6 & 71 & 44.4 & 160 \\
\hline
\end{tabular}




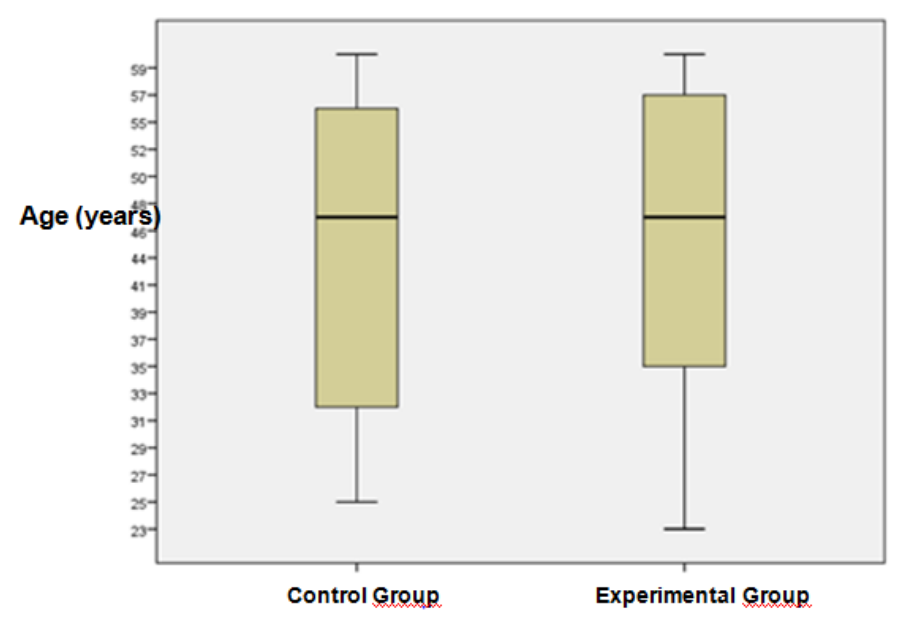

Graph I Age Distribution.

This observation is interesting because somehow, albeit indirect, shows that eating habits in this particular population aren't variable and that the alterations in lipid levels are not due to the intake of energy dense foods (Table 2).

The Body Mass Index also remained unchanged during treatment. This may be due the study population was within normal limits,

according to their age, height and weight and therefore it is likely that differences should not be observed in the values of the final measurements. In total agreement with previous observations, we found that none of the individuals included in this study suffered changes in the values of the systolic or diastolic blood pressure before or after treatment (Table 2).

Table 2 Groups Distribution Results

\begin{tabular}{|c|c|c|c|c|}
\hline & Maximum value & Mean value & Minimum value & Standard deviation \\
\hline \multicolumn{5}{|c|}{ Weight } \\
\hline Baseline & $78.4 \mathrm{~kg}$ & $62.8 \mathrm{~kg}$ & $50.5 \mathrm{~kg}$ & 6.17 \\
\hline Endpoint & $77.5 \mathrm{~kg}$ & $66.2 \mathrm{~kg}$ & $48.7 \mathrm{~kg}$ & 6.13 \\
\hline \multicolumn{5}{|c|}{ Body mass index } \\
\hline Baseline & $24.91 \mathrm{~kg} / \mathrm{m}^{2}$ & $23.75 \mathrm{~kg} / \mathrm{m}^{2}$ & $18.94 \mathrm{~kg} / \mathrm{m}^{2}$ & 0.91 \\
\hline Endpoint & $24.46 \mathrm{~kg} / \mathrm{m}^{2}$ & $23.31 \mathrm{~kg} / \mathrm{m}^{2}$ & $18.37 \mathrm{~kg} / \mathrm{m}^{2}$ & 0.86 \\
\hline \multicolumn{5}{|c|}{ Systolic pressure } \\
\hline Baseline & $122 \mathrm{~mm} / \mathrm{Hg}$ & $111.45 \mathrm{~mm} / \mathrm{Hg}$ & $100 \mathrm{~mm} / \mathrm{Hg}$ & 7.52 \\
\hline Endpoint & $120 \mathrm{~mm} / \mathrm{Hg}$ & $110.63 \mathrm{~mm} / \mathrm{Hg}$ & $100 \mathrm{~mm} / \mathrm{Hg}$ & 6.51 \\
\hline \multicolumn{5}{|c|}{ Diastolic pressure } \\
\hline Baseline & $80 \mathrm{~mm} / \mathrm{Hg}$ & $70.18 \mathrm{~mm} / \mathrm{Hg}$ & $60 \mathrm{~mm} / \mathrm{Hg}$ & 8.04 \\
\hline Endpoint & $80 \mathrm{~mm} / \mathrm{Hg}$ & $69.03 \mathrm{~mm} / \mathrm{Hg}$ & $60 \mathrm{~mm} / \mathrm{Hg}$ & 7.39 \\
\hline \multicolumn{5}{|c|}{ Glucose levels } \\
\hline Baseline & $108 \mathrm{mg} / \mathrm{dl}$ & $98.5 \mathrm{mg} / \mathrm{dl}$ & $78 \mathrm{mg} / \mathrm{dl}$ & 7.93 \\
\hline Endpoint & $102 \mathrm{mg} / \mathrm{dl}$ & $87 \mathrm{mg} / \mathrm{dl}$ & $75 \mathrm{mg} / \mathrm{dl}$ & 8.13 \\
\hline \multicolumn{5}{|c|}{ Cholesterol levels } \\
\hline Baseline & $328 \mathrm{mg} / \mathrm{dl}$ & $246.7 \mathrm{mg} / \mathrm{dl}$ & $210 \mathrm{mg} / \mathrm{dl}$ & 23.7 \\
\hline Endpoint & $268 \mathrm{mg} / \mathrm{dl}$ & $218 \mathrm{mg} / \mathrm{dl}$ & $1 \mid 3 \mathrm{mg} / \mathrm{dl}$ & 20.14 \\
\hline \multicolumn{5}{|c|}{ Triglycerides levels } \\
\hline Baseline & $390 \mathrm{mg} / \mathrm{dl}$ & $246 \mathrm{mg} / \mathrm{dl}$ & $175 \mathrm{mg} / \mathrm{dl}$ & 45.6 \\
\hline Endpoint & $297 \mathrm{mg} / \mathrm{dl}$ & $176.5 \mathrm{mg} / \mathrm{dl}$ & $110 \mathrm{mg} / \mathrm{d} \mid$ & 45.2 \\
\hline
\end{tabular}


Regarding serum glucose, considering the values mentioned in materials and methods, a slight upward trend in individuals who formed the experimental group, prior to receiving the diet is observed. While the median is within normal limits before starting treatment, there was a slight, but not significant decrease, in serum glucose concentration in both groups at endpoint (Table 2).

The initial concentration of cholesterol before treatment in the experimental group was $270 \mathrm{mg} / \mathrm{dl}$, this value decreased significantly after one month of intake of Opuntia Cactaceae to $205 \mathrm{mg} / \mathrm{dl}(\mathrm{P}<0.05)$. This result is highly relevant because it's possible that the intake of Opuntia Cactaceae exerts a direct hypocholesterolemic effect (Graph 2) (Table 2)

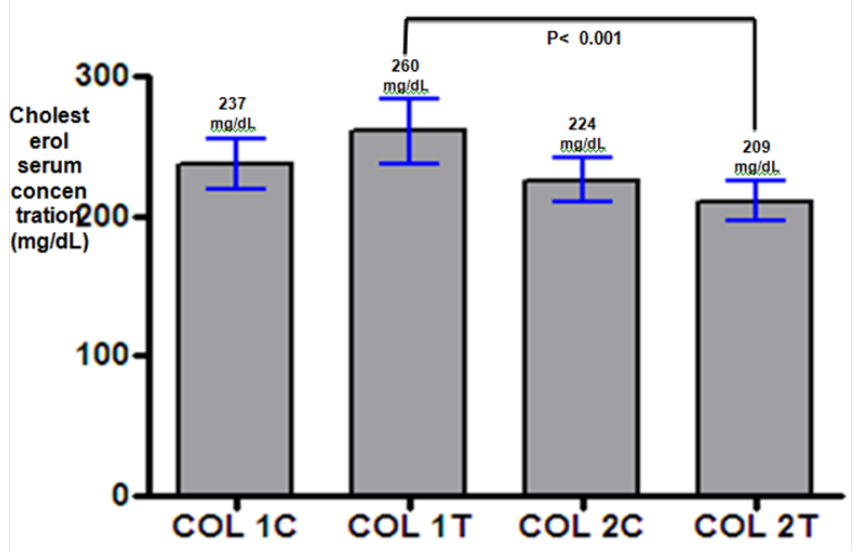

Graph 2 Univariated analysis of serum cholesterol levels.

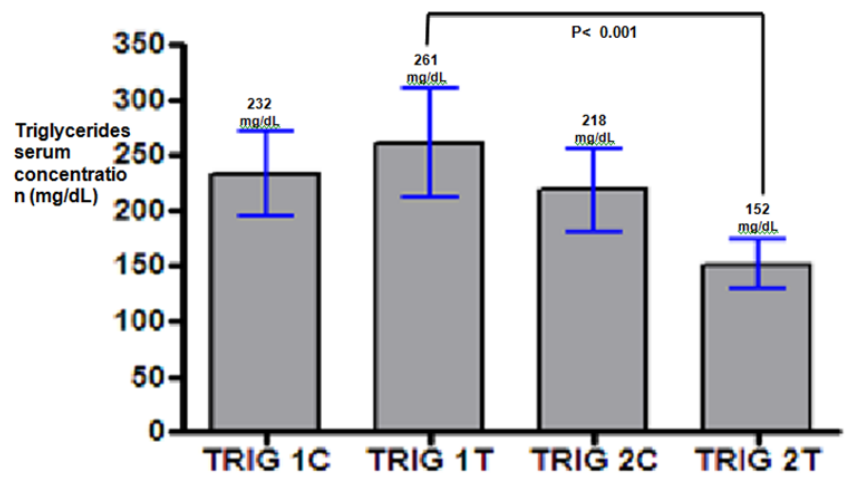

Graph 3 Univariated Analysis of Serum Triglycerides Levels.

The most striking result of all is related to the significant decrease in serum triglyceride concentration after intake of Opuntia Cactaceae. The control group showed no difference between the initial and final values, whereas the experimental group, which had a slight increase in basal concentration of cholesterol $(270 \mathrm{mg} / \mathrm{dl})$ showed a decrease of almost $50 \%$ in values at endpoint $(150 \mathrm{mg} / \mathrm{dl})(\mathrm{p}<0.001)(\mathrm{Graph} 3$ $\&$ Table 2).

\section{Conclusion}

Because of the properties of the Opuntia Cactaceae, cyaniding (a type of flavonoid), mucilage and pectin, beneficial results were obtained during the study. Pectin reduces in a significant way the intestinal absorption of lipids, and with cyaniding they exert an inhibitory effect on the liver X receptors (Jun, Hoang \& Yeo 2013). The preparation of the Opuntia Cactaceae during the study was also a key factor. These two characteristics made a big difference between the experimental and control groups regarding the values of cholesterol and triglycerides obtained at the end of the study. In this study the effectiveness of a normal calorie diet supplemented with Opuntia Cactaceae through biochemical parameters (total serum cholesterol and triglycerides) was assessed, however, it requires further study in which the long term impact of these nutritional therapies is to be evaluated, as well as the in vivo metabolism in the intestine of the fiber of the cactus. The favorable results of this study relied heavily on the good attachment of the subjects, as well as the continuous monitoring of personnel in charge. It is vital to design tools necessary for good adherence to nutritional therapy proposed in this study for future participants of similar projects. The Opuntia Cactaceae should be recognized not only for its properties of lipid- lowering effects and its high fiber content, but also as a food that contains many elements that may give other beneficial effects.

\section{Acknowledgements}

To Doctor Luis Felipe Montaño Estrada and Doctor José Manuel Lozano Sánchez, for their endless support at conducting this trial and for their love of science.

\section{Conflict of interest}

Author declares that there is no conflict of interest.

\section{References}

1. Vinueza R, Boissonnet CP, Acevedo M, et al. Dyslipidemia in seven latin american cities:CARMELA study. Prev Med. 2010;50(3):106-111.

2. Cols MHy. Prevalencia y comorbilidad de dislipidemias en adultos. Rev Med Inst Mex Seguro Soc. 2007;45(5):469-475.

3. Segundo Morán, Gustavo Rodríguez-Leal, Martha Helena Ramos, et al Concentración de colesterol plasmático: prevalencia y factores asociados con hipercolesterolemia. Estudio transversal en la unidad de diagnóstico médica sur. Rev Médica Sur. 2000;7(1):6-9.

4. Nielsen S, Guo Z, Jhonson C, et al. Splachnic lipolysis in human obesity. J clin Invest. 2004;113(11):1582-1588.

5. Brunzell JD. Hypertriglyceridemia. $N$ Engl J Med 2007;357(10):1009-1017.

6. Galisteo M, Duarte J, Zarzuelo A. Effects of dietary fibers on disturbances clustered in the metabolic syndrome. J Nutr Biochem. 2008;19(2):71-84.

7. Kim YI. Aga technical review: Impact of dietary fiber on colon cancer occurrence. Gastroenterology. 2000;118(6):1235-1257.

8. Tungland B, Meyer D. nondigestible oligo-and polysaccharides (Dietary fiber): Their physiology and role in human health and food. Comprenensive reviws in food scisence and food safety. 2002;3:9-109.

9. Peña Valdivia C, Sanchez Urdaneta A. Nopalito and cactus pear (Opuntia spp.) polysaccharudes: mucilage and pectin. Acta horticulturae. 2006;728(4):241-247.

10. Guo Xin H, Guo Rong C, Hui X, et al. Activation of the AMP activated protein kinase by short- chain fatty acids is the main mechanism underlying the beneficial effect of a high fiber diet on the metabolic syndrome. Med Hypotheses. 2010;74(1):123-126.

11. CH C. Fibres alimentaires: que deviant l'hypothése de Burkitt? Cah Nutrition Diététique. 1998;33:95-104. 
12. Trantwein EA, Kunath Ran A, Erbersdobler HF. Increased fecal bile acid excretion and changes in the circulating bile acid pool are involved in the hypocholesterolemic and gallstone- preventive actions of psyllium in hamsters. J Nutr. 1999;129(4):896-902.

13. Davy BM, Melby CL. The effect of fiber rich carbohydrates on featyres of Syndrome X. J Am Diet Assoc. 2003;103(1):86-96.
14. Luley C, Ronquist G, Reuter W, et al. Point of care testing of triglycerides: Evaluation of the Accutrend Triglycerides System. Clin Chem. 2000;46(2):287-291.

15. Panel on the definition of dietary fiber SCotSEodri. Proposed definition of dietary fiber. Washington, USA: National Academy Press; 2001. 